Article

\title{
Two New Ways of Documenting Miniature Incisions Using a Combination of Image-Based Modelling and Reflectance Transformation Imaging
}

\author{
Dag-Øyvind E. Solem * and Erich Nau
}

Department of Digital Documentation of Heritage and Landscape, Norwegian Institute of Cultural Heritage Research, NIKU Hovedkontor, Postboks 736 Sentrum, 0105 Oslo, Norway; erich.nau@niku.no

* Correspondence: dag-oyvind.engtro@niku.no; Tel.: +47-452-83-585

Received: 23 April 2020; Accepted: 16 May 2020; Published: 19 May 2020

\begin{abstract}
Digital 3D documentation methods such as Image-Based Modelling (IBM) and laser scanning have become increasingly popular for the recording of entire archaeological sites and landscapes, excavations and single finds during the last decade. However, they have not been applied in any significant degree to miniature incisions such as graffiti. In the same period, Reflectance Transformation Imaging (RTI) has become one of the most popular methods used to record and visualize this kind of heritage, though it lacks the benefits of 3D documentation. The aim of this paper is to introduce two new ways of combining IBM and RTI, and to assess these different techniques in relation to factors such as usability, time-efficiency, cost-efficiency and accuracy. A secondary aim is to examine the influence of two different 3D processing software packages on these factors: The widely used MetaShape (MS) and a more expensive option, RealityCapture (RC). The article shows that there is currently no recording technique that is optimal regarding all four aforementioned factors, and the way to record and produce results must be chosen based on a prioritization of these. However, we argue that the techniques combining RTI and IBM might be the overall best ways to record miniature incisions. One of these combinations is time-efficient and relatively cost-efficient, and the results have high usability even though the 3D models generated have low accuracy. The other combination has low time- and cost-efficiency but generates the most detailed 3D models of the techniques tested. In addition to cost-efficiency, the main difference between the 3D software packages tested is that RC is much faster than MS. The accuracy assessment remains inconclusive; while RC generally produces more detailed 3D models than MS, there are also areas of these models where RC creates more noise than MS.
\end{abstract}

Keywords: digital documentation; IBM; reflectance transformation imaging (RTI); structure from motion (SfM) photogrammetry; archaeology; graffiti; epigraphy

\section{Introduction}

Miniature incisions such as old graffiti are often located in places exposed to natural and/or human made wear and tear. Surveys and studies have shown that these vulnerable traces of history can be a rich source of information [1-3], but the traditional ways of recording this heritage-such as frottaging, tracing, casting and raking light photography-are often time-consuming, inaccurate and in some cases destructive [4]. During the last decade, Reflective Transformation Imaging (RTI) has become a widely utilized method to record surfaces with miniature incisions [5-8]. This low-cost and time-efficient method generates highly detailed 2.5D models (see Section 2.2.2), which may be manipulated to showcase the surface elevations even further. However, this method lacks many of the benefits of 3D modelling, such as complex ways of analyzing the results and the options to 
scale, georeference, combine and easily convey the models. During the same period, increasingly detailed digital documentation methods used in archaeology have provided the opportunity for quicker and better surveying than just a decade ago. This new technology has become so accessible that it has in many ways revolutionized the workflow of archaeological excavations. It has reduced the time needed for on-site drawings and measurements, as well as made the results of excavations easier to analyze and convey [9]. One of the most popular digital documentation methods used by archaeology today is Imaged-Based Modelling (IBM), which creates 3D models from overlapping images. However, it has only occasionally been used to record miniature incisions such as graffiti $[4,5]$. The fact that these methods are mainly used separately reduces their potential impact in supporting study and analysis [10], and the projects that do use both methods tend to see them as complimentary and to be used separately where best suited [5,11,12]. For years there have been projects that aim to make software or processing techniques that can generate, convey and/or analyze IBM and RTI combined [10,13-16]. However, as these are still in development or have limited utility, this article aims to introduce two new and quite simple techniques of combining these methods, as well as to compare them with traditional IBM and RTI regarding usability, time-efficiency, cost-efficiency and accuracy. There are many 3D processing software packages to choose from. A secondary aim of this article is to examine the influence of two widely used 3D processing software packages, MetaShape (MS) and RealityCapture (RC) on the factors mentioned above.

There are numerous examples of comparative analyses regarding digital 3D documentation $[9,17,18]$, and also some that focuses on documenting small incisions typically preserved on stationary surfaces $[4,5,19]$. However, these studies do not include ways to combine IBM and RTI. Furthermore, the rapid development of both hardware and software makes this a type of project that should be repeated from time-to-time. This is not a complete comparative analysis of all ways to record these kinds of surfaces; there are simply too many possible variations in terms of equipment, ways in which to use them and the software used to post-process the data. Rather, two novel ways of combining IBM and RTI are compared with examples of standard ways of using these methods.

\section{Materials and Methods}

\subsection{The Documented Surfaces}

The two studied surfaces are on two 13th century building stones, both of which derive from the Nidaros Cathedral in Trondheim, Norway.

Surface A (Figure 1) is located on a building stone which was originally part of a wall pillar in the cathedral. The documented side measures c. 52 by $20 \mathrm{~cm}$, and has incisions with thicknesses ranging from c. 0.5 to $5 \mathrm{~mm}$. The graffiti consists of crosses and other symbols. The crosses are orientated in differing directions, indicating either that the surface originally faced upwards and was accessible from different angles, or that it was later reused in a different position. The stone is presently in a storage facility, placed close to the floor with the recorded side in a vertical position. The closeness to the floor made it impossible to take pictures or illuminate the surface from low angles, but this do not seem to have influenced the results noticeably.

Surface B (Figure 2) is a c. 30 by $24 \mathrm{~cm}$ part of a building stone still in its original position in one of Nidaros Cathedral's outer walls (Figure 2). The recorded surface bears, among other graffiti, a runic inscription interpreted as "Lavrans owns". The inscription, combined with a large horizontal groove in the same wall, suggests that an altar mentioned in a 15th century documentary source was located here (Lavrans is an indigenous and medieval form of Laurentius). The runic inscription, situated c. $40 \mathrm{~cm}$ above and to the left of the groove in the wall, could have been an unofficial dedication inscription for commoners who were not fluent in Latin. 


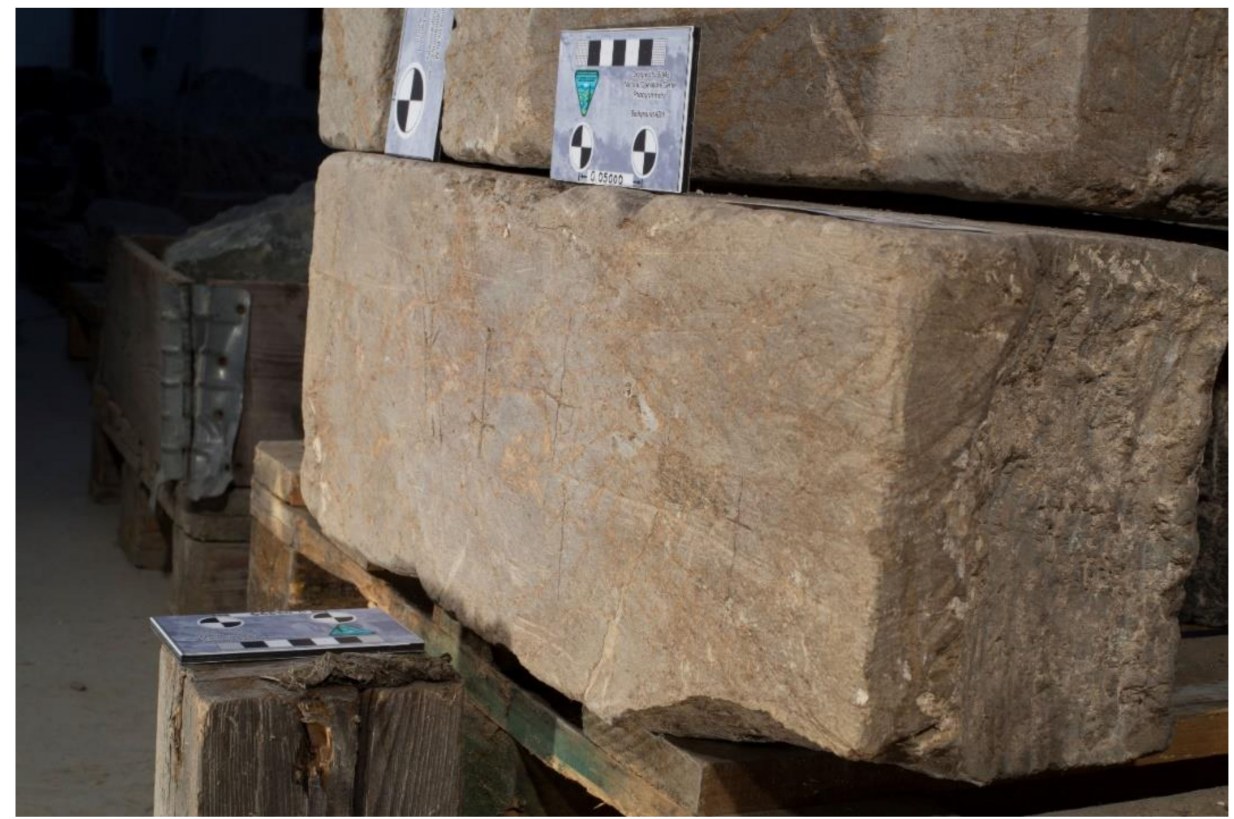

Figure 1. Surface A, located on a 13th century building stone currently in a storage facility.

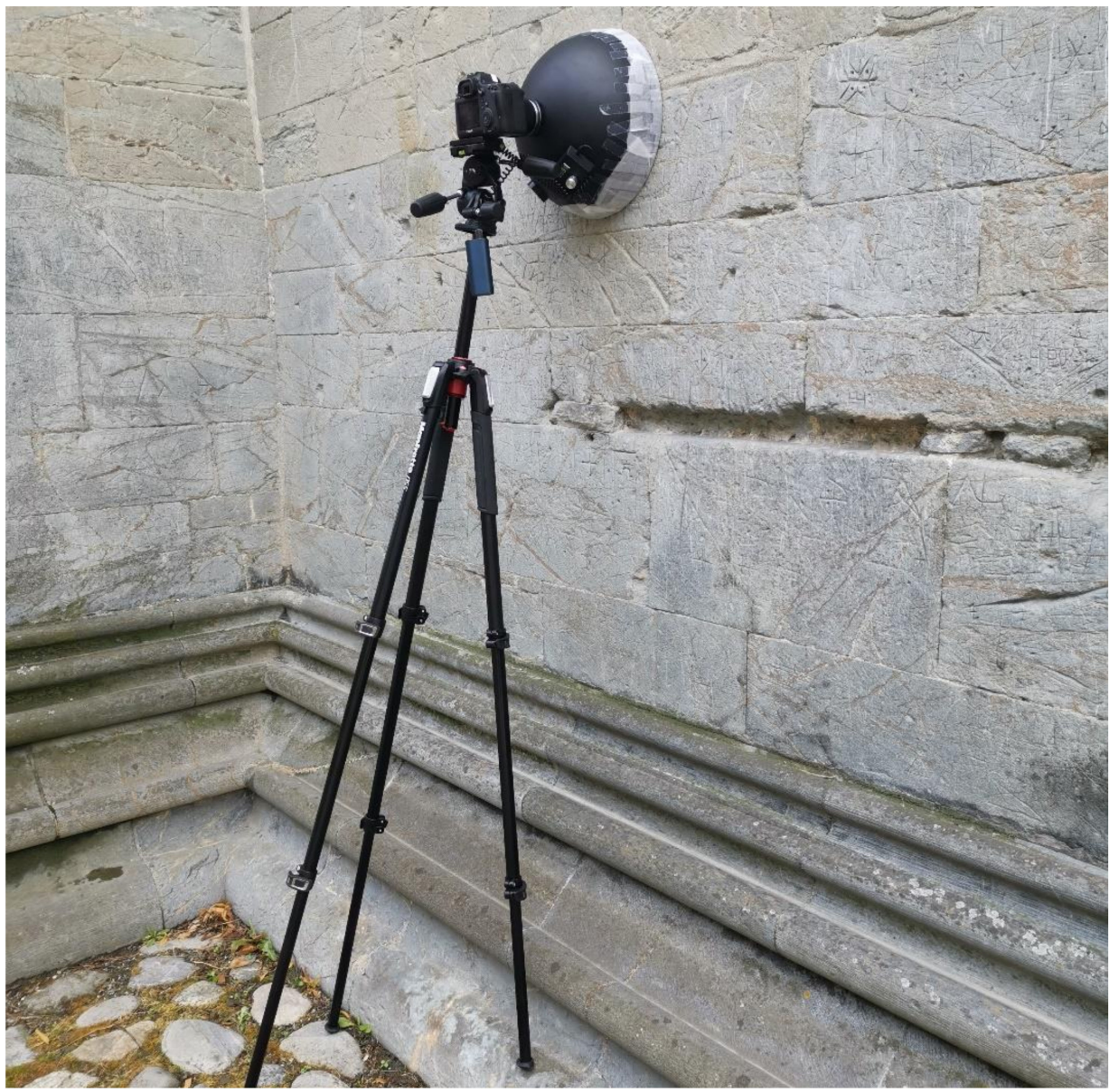

Figure 2. Image acquisition of Surface B, on a 13th century building stone still in original position. 


\subsection{Methods}

The methods used to record the chosen surfaces are Image-Based Modelling, two variations of Reflectance Transformation Imaging, and two ways of combining IBM and RTI (Combo 1 and 2). These will be further described below. All 3D models were made or attempted made using two 3D processing software packages, MetaShape and RealityCapture. The specifications and settings of hardware used are listed in Appendix A, while the specifications and settings of software used are listed in Appendix B. The equipment used and their costs are listed in Appendix C. All source images, as well as all figures, are available in full resolution as Supplementary Materials online.

\subsubsection{Image-Based Modelling}

IBM is a technique based on the concept of creating 3D models from overlapping pictures with known or assumed orientations. This method is often incorrectly referred to as Structure from Motion (SfM) photogrammetry, but as shown below this is technically only a part of the process [20]. Most 3D processing software packages follow this basic procedure [20,21]:

1. Alignment-The positions of the camera are calculated for each picture based on homologous points where the pictures overlap.

2. 3D point cloud generation - the matching points are used to create a 3D sparse point cloud consisting of $\mathrm{X}-, \mathrm{Y}$ - and $\mathrm{Z}$-data by using SfM. Then, dense image matching algorithms are used to densify the point cloud.

3. 3D mesh reconstruction-The relevant points in the dense point cloud are connected by triangles, creating a 3D mesh.

4. Texture projection-The 3D mesh is textured by projecting colors from the source images.

Image acquisition for the IBM models were done with a camera mounted on a tripod. To record surface A, pictures were taken from a wide variety of angles, at c. 0.7 - 1 meter. Great care was taken to get every picture as sharp as possible, so the whole session lasted over an hour. Surface B was photographed at c. $30 \mathrm{~cm}$ and angled straight onto the surface, which allowed for using the same camera settings throughout the photo session.

\subsubsection{Reflectance Transformation Imaging}

RTI is a method of capturing and enhancing elevation information on a surface. During image acquisition the camera remains static, but the illumination is different for each picture. RTI processing software, most commonly RTIBuilder, is used to make 2.5D models from the images, i.e., 2D graphical projections that uses height information to create the illusion of 3D viewing surfaces or artefacts. Unlike 3D models, the user is restricted to seeing the models from the singular angle from which they were photographed [19]. To separate these from other types of 2.5D models, such as Digital Terrain Models (DTM) and Digital Elevation Models (DEM), they will be referred to here as RTI models. Another RTI software, most commonly RTIViewer, is used to view and manipulate the models by changing light direction and/or rendering mode. The rendering modes display and enhance the surface elevations of the RTI models in various ways. RTI is an improvement of the traditional raking light method of photographing graffiti, i.e., image acquisition with illumination from one sharp angle. While this technique illuminates one side of the surface it often obstructs others [6]. More importantly, the models also contain estimated information regarding the shapes and textures of the recorded surfaces. 
There are two main techniques of RTI image acquisition, Highlight RTI (H-RTI) and Rigged Light RTI (RL-RTI). When using H-RTI, a light source is moved for each picture taken and the angle of the light source is captured in the reflection of one or more spheres situated somewhere within the images [22]. The pictures should be taken with lighting from an even spread of angles and with the same distance to the surface. This distance should be about two to four times the length of the documented surface [23]. RTIBuilder uses the reflections in the spheres to calculate the angles the pictures were taken from. An optional RTI kit, including reflective spheres in different sizes and equipment to rig these for photo sessions is available from www.culturalheritageimaging.org. Since the method is based on manipulating lights and shadows the pictures are normally taken in dark or dim conditions. Alternatively, neutral density filters in combination with a flash may be used to achieve better lightning conditions [6].

With the RL-RTI technique, numerous light sources are rigged in optimal angles and distances, typically in an RTI dome. The domes have the additional advantage of blocking out unwanted light, and some domes may be mounted on tripods to take pictures vertically. The rigged light systems have information about the light sources' distances and angles stored in a light positioning-file used by the RTI software, making the reflecting spheres unnecessary. This also speeds up the post-processing, since the software does not have to calculate this information for each new session. In this study, a $35 \mathrm{~cm}$ diameter RTI dome with 50 fixed LED lights was used. The RTI dome was produced by Tomasz Lojewski at the laboratory at AGH University of Science and Technology, in Krakow, Poland [24]. The camera was connected to the dome, and the photo sessions were set up and initiated by the light regulator and shutter control unit on the dome. During each image acquisition, 50 pictures were taken automatically with a different LED-light illuminating the surface for each picture. The post-processing of the pictures taken with the RL-RTI technique were done using RTI Processor, a software specialized for images acquired this way. Although there are alternative RL-RTI setups, the term will, from here on, refer to images acquired by using an RTI dome.

\subsubsection{IBM and RTI Combined}

Two ways of combining IBM and RTI were tested, both based on overlapping images acquired using the RL-RTI technique. The images for both combination methods were acquired by photographing the surfaces with the RTI dome, taking 50 pictures from each of the 28 (Surface A) and 25 (Surface B) different positions. The 50 pictures from each position had 50 different illuminations. This allowed for a large number of pictures with different illumination, and the question was whether this would benefit the resulting models. A $28 \mathrm{~mm}$ lens was chosen to cover a large area for each photo session, while sacrificing some of the accuracy a narrower angle of lens would have provided. The first way to combine these methods (Combo 1) was to process these images unaltered using IBM software. The second way (Combo 2) was to process the images from each camera position separately using RTI software before further processing with IBM software. To do this, these steps were taken:

1. Each of the 28 and 25 sets of 50 pictures of Surface A and B were processed into 28 and 25 RTI models using RTI Processor.

2. Two JPGs of each RTI models were exported in RTIViewer, using two of the different rendering modes available in this software; Normals Visualization and Dynamic Multi Light. This step will be elaborated below.

3. The 56 and 50 JPG exports were processed by IBM software. 
It was discovered that most of the Polynomial Texture Maps (PTMs) available in RTIViewer distort the end results so much that IBM software is not able to recognize them as overlapping images. The Normals Visualization mode is ideal, because it substitutes all the original color information with a color representation of each pixel's surface orientation [23]. To allow the IBM software to be able to recognize the overlapping pictures the false colorings were removed in Photoshop. A disadvantage of this method is that the color coding used by the software is so finely tuned that even slight slopes on the recorded surfaces will often result in these parts being colored so light or dark that the details disappear. To complement these areas, another rendering mode was also used for export-Dynamic Multi Light. These pictures retained their original colors, but the software had combined illumination from many different angles to optimize their sharpness and brightness [23]. Both 3D software packages had problems aligning the Normals Visualization exports, so the Dynamic Multi Light exports were aligned first, then their positions were exported and reused for the rest of the pictures.

\section{Results}

\subsection{Usability}

All the tested methods have different constraints and advantages that influence their usability's. For instance, IBM has the advantage of being well suited for recording surfaces of most shapes, but to do this ample space is often needed to take pictures from all necessary angles. This is not necessary for recording flat surfaces, however, as demonstrated by the recording of Surface B which was photographed from many positions but only one angle (straight on). Another constraint to IBM is that to record as many details as possible the surfaces should ideally be well-lit and evenly illuminated [25]. It is often difficult to achieve this, especially when recording large surfaces. In contrast, H-RTI demands near darkness to avoid ambient light degrading the result, if no neutral density filters are used. This complicates the photo session, when one has to carefully maneuver around the camera and the tripod with a remote shutter, a light source and a rule or a wire to maintain a constant distance between the light source and the surface. Even a slight deviation in the setup requires the process to be started over again. Since the distance from which the surface is lit should be about two to four times the width of the surface, the size of the recorded surface will often be limited by the surroundings. RL-RTI image acquisition excludes ambient light and brings its own illumination. The RTI dome also has less need for workspace than H-RTI, because the tripod only has to move slightly between each round of photos and nothing else has to be moved. On the other hand, the dome forces the camera to be perpendicular to the surface, which increases the need for even surfaces. The distance from the camera to the surface is so small that even small deviations will cause areas to become out of focus. With our dome, the distance between the lens and the recorded surface was $18 \mathrm{~cm}$, so height deviations of c. $+-1 \mathrm{~cm}$ on the recorded surface would not be properly recorded. For Combo 1 this problem may be mitigated to some extent by using a shorter focal length or expanding the focus and decreasing shutter speed. However, Combo 2, H-RTI and RL-RTI use RTI software which works only for recording flat or nearly flat surfaces. If the lights and shadows used by the software to estimate surface elevations are obstructed by large deviations the result will be severely negatively affected [5,24].

RL-RTI restricts the size of the recorded surface even more than H-RTI, because only the area inside the scope of the dome (or even just a part of it, depending on the lens used) will be recorded. The RTI software is not able to combine and manipulate RTI models simultaneously, which means that RTI models of overlapping parts of a surface have to be manipulated and exported separately to be presented together. Often the most interesting rendering modes in RTIViewer are the ones where the original colors are or may be removed and the elevations on the surfaces are most pronounced: Specular Enhancement, Normal Unsharp Masking and the Normals Visualization. With the exception of the Normals Visualization-which has its own previously mentioned limitations-these modes fade out the outer areas of the RTI models, because these areas were not photographed with light from enough angles to have a well estimated topography. That means that there has to be a high degree 
of overlap between each dome position to be able to export these results for further IBM processing. The need for overlap is not as severe for Combo 1, which uses the original pictures for IBM.

The resulting models also have different usability. The RTI models may be illuminated from all angles and manipulated to showcase elevation differences, but there is not much else they can be used for. On the other hand, 3D models have a wide range of uses. They may be rotated and shown from different angles, and easily shared for interactivity online. Furthermore, they can be scaled and georeferenced, which make them suitable for measurements and other analysis. They can also be easily combined or compared to other 3D models.

\subsection{Time-Efficiency}

Time spent on the tested methods varied considerably, both on-site (Table 1) and in post-processing (Table 2). Generally speaking, the RTI methods were more time-efficient than the IBM method. IBM image acquisition of miniature incisions on flat walls may be sped up somewhat by taking all the pictures from the same angle, as was done when recording Surface B and not from many different angles as was done with Surface A. During H-RTI image acquisition only the lighting source is moved for each picture taken, and Surface A was recorded in less than 15 minutes. The RL-RTI image acquisition of the same surface lasted 7.5 times longer, because the process needs many overlapping photo positions when recording surfaces larger than the RTI dome-especially when the result is also intended for IBM post-processing, as these images were.

Table 1. The table illustrates the on-site time-efficiency of each method on each recorded surface. In general, Reflective Transformation Imaging (RTI) image acquisition is faster than Imaged-Based Modelling (IBM) image acquisition. However, when used for larger surfaces with the intention of combining the results, using Rigged Light RTI (RL-RTI) requires photographing from many positions with a lot of overlap-making the combination methods slower on-site.

\begin{tabular}{ccccccc}
\hline & \multicolumn{3}{c}{ Surface A } & \multicolumn{3}{c}{ Surface B } \\
\hline Method & $\begin{array}{c}\text { Pictures } \\
\text { Taken }\end{array}$ & Positions & Time Used & $\begin{array}{c}\text { Pictures } \\
\text { Taken }\end{array}$ & Positions & Time Used \\
IBM & 109 & 109 & $1 \mathrm{hr} \mathrm{10 \textrm {min }}$ & 171 & 171 & $45 \mathrm{~min}$ \\
H-RTI & 71 & 1 & $14 \mathrm{~min}$ & Not tested & - & - \\
RL-RTI Combo 1 Combo 2 & 1400 & 28 & $105 \mathrm{~min}$ & 1250 & 25 & $100 \mathrm{~min}$ \\
\hline
\end{tabular}

Table 2. The table illustrates the time-efficiency of post-processing for each method on each recorded surface. The table shows that RTI post-processing is much faster than IBM post-processing, though the latter is greatly improved by using RealityCapture instead of MetaShape. Combo 1 uses IBM software to post-process large number of pictures and has low time-efficiency. The post-processing done with Combo 2 is done in two stages; the original pictures are first processed by RTI software, subsequentially the resulting images are post-processed by IBM software. This process is a lot more time-efficient, since the IBM software processes a smaller number of pictures.

\begin{tabular}{|c|c|c|c|c|c|}
\hline \multirow[b]{2}{*}{ Method } & \multirow[b]{2}{*}{ Software } & \multicolumn{2}{|c|}{ Surface A } & \multicolumn{2}{|c|}{ Surface B } \\
\hline & & Pictures & Time Used & Pictures & Time Used \\
\hline \multirow[b]{2}{*}{ IBM } & MetaShape & 109 & $16 \mathrm{~h}, 20 \mathrm{~min}$ & 171 & $16 \mathrm{~h}, 50 \mathrm{~min}$ \\
\hline & RealityCapture & 109 & $1 \mathrm{~h}, 28 \mathrm{~min}$ & 171 & $1 \mathrm{~h}, 31 \mathrm{~min}$ \\
\hline H-RTI & RTIBuilder & 71 & $18 \mathrm{~min}$ & Not tested & - \\
\hline RL-RTI & RTI Processor & 1400 & $2 \mathrm{~h}$ & 1250 & $2 \mathrm{~h}, 5 \mathrm{~min}$ \\
\hline \multirow{2}{*}{ Combo 1} & MetaShape & 1400 & Failed & 1250 & Failed \\
\hline & RealityCapture & 1400 & $18 \mathrm{~h}, 46 \mathrm{~min}$ & 1250 & $8 \mathrm{~h}$ \\
\hline \multirow{3}{*}{ Combo 2} & $\begin{array}{c}\text { RTI Processor } \\
\text { (Preprocessing and exports) }\end{array}$ & 1400 & $3 \mathrm{~h}$ & 1250 & $2 \mathrm{~h}, 45 \mathrm{~min}$ \\
\hline & MetaShape & 56 & $8 \mathrm{~h}, 12 \mathrm{~min}$ & 50 & $6 \mathrm{~h}, 52 \mathrm{~min}$ \\
\hline & RealityCapture & 56 & $34 \mathrm{~min}$ & 50 & $19 \min$ \\
\hline
\end{tabular}


The post-processing of H-RTI pictures was also a quite time-efficient procedure. In theory, the RL-RTI post-processing is much faster because RTI Processor omits many of the calculations needed for the H-RTI technique, since the position of the camera and the illumination is known in advance. However, the large number of pictures caused post-processing the RL-RTI pictures to last much longer than the H-RTI process. The time-efficiency of post-processing with the Combo 1 and Combo 2 methods varied greatly. When using Combo 1 all the original pictures were post-processed using IBM software, while only $1 / 50$ the number of pictures had to go through this process when using Combo 2. When post-processing 1400 and 1250 pictures for IBM (Combo 1), RealityCapture worked slowly and MetaShape was stopped after the initial alignment steps lasted over 15 hours. However, when pre-processed by RTI Processor before these results were exported and subsequently processed by the IBM software (Combo 2), the lower number of pictures made the post-processing much more efficient-for instance, the total post-processing of Surface A lasted 3 hours and 34 minutes using Combo 2, while it lasted 18 hours and 46 minutes when using Combo 1. The lower number of pictures also allowed MetaShape to be used for Combo 2, in this case the total post-processing of Surface A lasted $11 \mathrm{~h}$ and $12 \mathrm{~min}$.

The time-efficiency difference between the 3D software packages was obvious, even though as mentioned previously MetaShape downscaled the dense cloud before mesh generation while RealityCapture did not. In the four instances both programs were used, RealityCapture was 11, 11, 14 and 28 times faster than MetaShape.

\subsection{Cost-Efficiency}

Both IBM and RTI are commonly seen as low-cost documentation methods in comparison to methods such as laser scanning and structured light scanning $[5,10]$. There is still quite a price difference between the tested methods, and especially for smaller institutions price often matters. The RTI methods cost less than the other three (Table 3). Since the necessary software is free, the relative cost of using RTI depends on what kind of camera equipment is used, whether to invest in a RL-RTI setup, and if so, which one. Larger domes would cover larger surfaces and may be more advanced but could also be substantially more expensive. The cost of using IBM also depends on the camera equipment used, but as seen in Table 3 the chosen software package was the most decisive factor in our case. Of the two programs tested, RealityCapture is four times more expensive than MetaShape Professional. However, both software packages are available with cheaper licensing options, and there are multiple other alternatives to these programs at different price ranges which may be considered.

Table 3. The cost of equipment and software used. The evaluation of cost is subjectively evaluated on the following scale: Low $(0-\$ 7000)$, moderate $(\$ 7000-\$ 14,000)$ or high $(\$ 14,000$ or more). See Appendix A for details. The prices are as of February 2020, some of which have been converted from Norwegian Kroner or Euro.

\begin{tabular}{|c|c|c|c|c|c|}
\hline Method & Equipment Cost & Software & Software Cost & Sum & Cost Evaluation \\
\hline IBM & $\$ 4400$ & $\begin{array}{l}\text { MetaShape } \\
\text { Professional }\end{array}$ & $\$ 3500$ & $\$ 7900$ & Moderate \\
\hline IBM & $\$ 4400$ & RealityCapture & $\$ 15,000$ & $\$ 19,400$ & High \\
\hline Combo 1 & $\$ 5873$ & $\begin{array}{l}\text { RealityCapture } \\
\text { RTI Processor }\end{array}$ & $\$ 15,000$ & $\$ 20873$ & High \\
\hline Combo 2 & $\$ 5873$ & $\begin{array}{l}\text { MetaShape } \\
\text { Professional } \\
\text { RTI Processor }\end{array}$ & $\begin{array}{l}\$ 3500 \\
\text { Free }\end{array}$ & $\$ 9373$ & Moderate \\
\hline Combo 2 & $\$ 5873$ & $\begin{array}{l}\text { RealityCapture } \\
\text { RTI Processor }\end{array}$ & $\begin{array}{l}\$ 15,000 \\
\text { Free }\end{array}$ & $\$ 20873$ & High \\
\hline H-RTI & $\$ 4350$ & RTIBuilder & Free & $\$ 4352$ & Low \\
\hline RL-RTI & $\$ 5873$ & RTI Processor & Free & $\$ 5773$ & Low \\
\hline
\end{tabular}




\subsection{Accuracy}

Evaluating the accuracy of these models, i.e., the level of detail is, in contrast to time-efficiency and cost efficiency, not adequate when based on quantifiable variables, because IBM generates 3D models, and RTI generates 2.5D RTI models. The amount of detail in a 3D model can be inferred by, for instance, the number of vertices; from the numbers in Table 4 we can assume that RealityCapture has generated more detailed models than MetaShape. This is because MetaShape, unlike RealityCapture downscales the point clouds before generating meshes [26]. This constraint may be bypassed by setting a Custom Face Count when creating a mesh in MetaShape. This option was unintentionally overlooked in this instance and will be subject for further analysis. All models were made with the highest default settings available, see Appendix B for details. Since the RTI models do not contain vertices, assessment of accuracy also needs to be carried out visually. For this article, visual comparisons were done in two ways. Selected details of all the 3D models were exported as OBJ-files, without the photographic texture maps in order to avoid the visual interference these creates. The models were scaled and aligned in CloudCompare, and an image of each model was then rendered with identical illumination in Blender. The corresponding details of the RTI models were exported in the Normals Visualization mode (described later) and converted to greyscale images with Photoshop. Since the 3D models in their entirety were too large for Blender, they were visualized with the Radiance Scaling shader in MeshLab.

Table 4. The number of vertices (in millions) in each of the 3D models generated. From these we can assume that the RealityCapture models are more accurate than the MetaShape models, though this should also be assessed visually. The Ground Sampling Distance (GSD) values indicate the level of details in the pictures the models are based on. These were calculated using Ground Sample Distance Calculator on www.3dflow.net.

\begin{tabular}{ccccc}
\hline Surface & Method & GSD & MetaShape & RealityCapture \\
\hline \multirow{3}{*}{ A } & IBM & $0.1 \mathrm{~mm}$ & $1.7 \mathrm{M}$ & $6.7 \mathrm{M}$ \\
& Combo 1 & $0.07 \mathrm{~mm}$ & Failed & $30.7 \mathrm{M}$ \\
& Combo 2 & $0.07 \mathrm{~mm}$ & $5.9 \mathrm{M}$ & $18.2 \mathrm{M}$ \\
\hline \multirow{2}{*}{ B } & IBM & $0.04 \mathrm{~mm}$ & $23.5 \mathrm{M}$ & $68.6 \mathrm{M}$ \\
& Combo 1 & $0.07 \mathrm{~mm}$ & Failed & $25 \mathrm{M}$ \\
& Combo 2 & $0.07 \mathrm{~mm}$ & $5.9 \mathrm{M}$ & $12.7 \mathrm{M}$ \\
\hline
\end{tabular}

As can be seen in Figures 3 and 4, the RTI models (Figures $3 \mathrm{c}$ and $4 \mathrm{~b}$ ) are clearly more detailed than the pure IBM models (Figure 3a). Of the 3D models, only the Combo 1 models (Figure 3b) come close to the accuracy of the RTI models. When compared to the "blueprints" of the RTI models, the $3 \mathrm{~d}$ models are less detailed and too smooth - many of the minor elevations and crevices in the weathered surfaces do not appear there. The accuracy differences are even more obvious on inspection of the close-ups (Figures 5 and 6). For instance, the ring encircling the arms in the ringcross on Surface A is very clear in the RTI models (Figure 5f,g) and the Combo 1 model (Figure $5 \mathrm{c}$ ), only partly visible in the IBM models (Figure 5a,b), and even less visible in the Combo 2 models (Figure $5 \mathrm{~d}, \mathrm{e}$ ). In general, the Combo 1 models are the most detailed and have the least amount of noise of the 3D models, which arguably make them the most visually appealing (see for instance Figure $6 \mathrm{c}$ in comparison to the other $3 \mathrm{D}$ models in the same figure). The models made using Combo 2 are very pixelated and are the least detailed ones (Figure 5d,e and Figure 6d,e). 


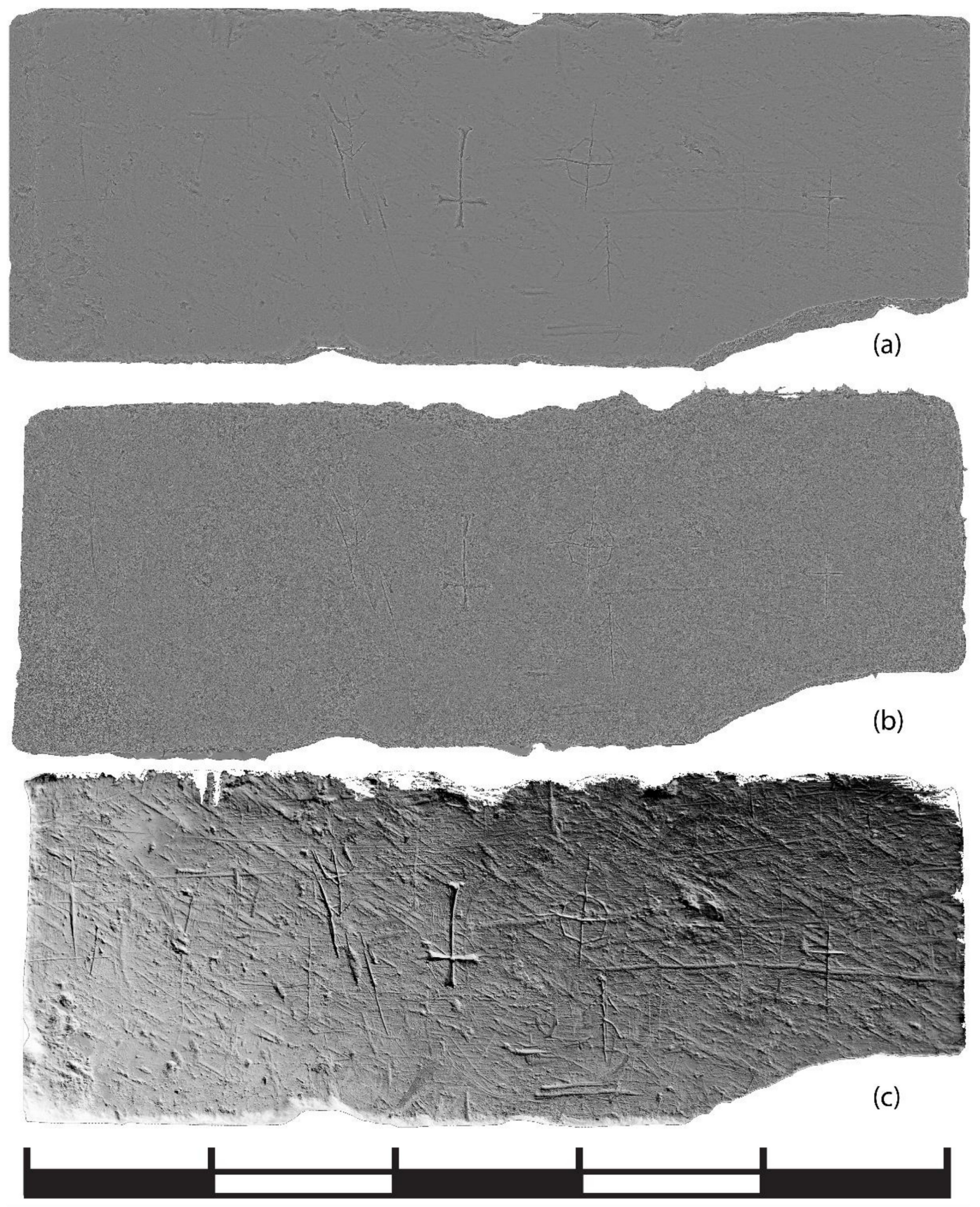

Figure 3. Surface A. (a) IBM-RealityCapture (RC); (b) Combo 1-RC; and (c) Highlight RTI (H-RTI). The scale shown is $50 \mathrm{~cm}$. The RTI model is the most detailed, while the Combo 1 is the most detailed of the 3D models. For practical purposes, only a selection of the results is shown here. All result images, including of the remaining methods, are available in full resolution online. 


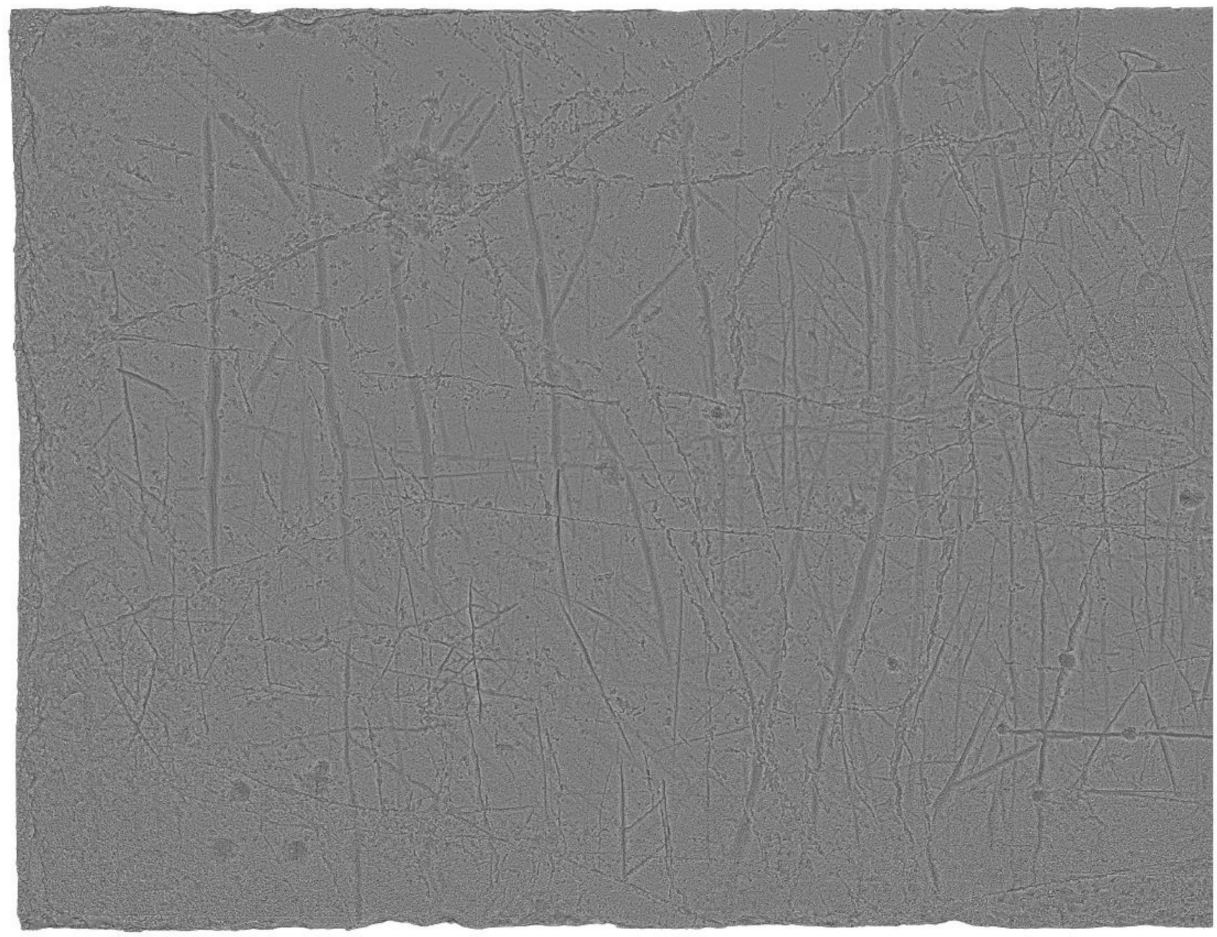

(a)

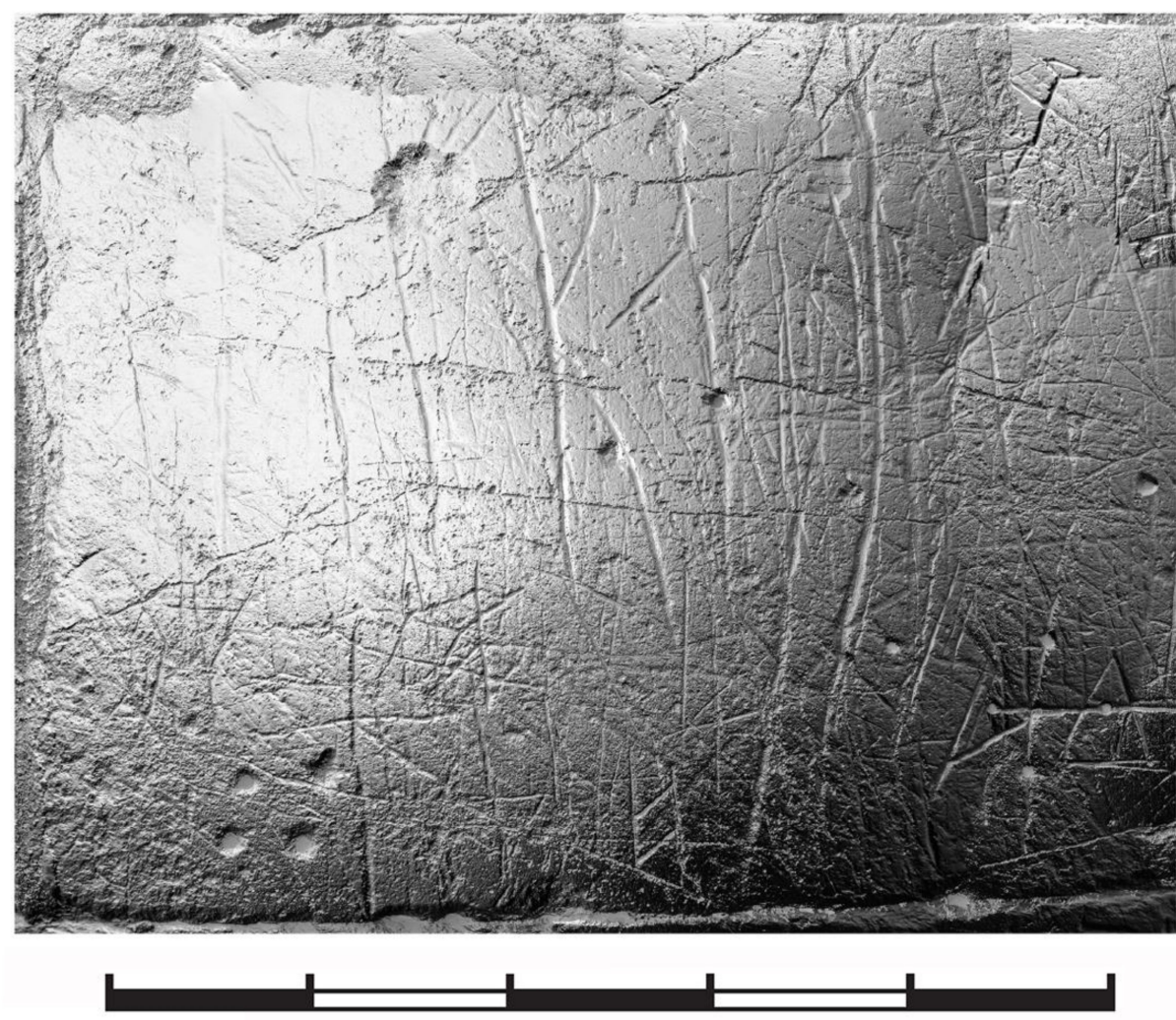

(b)

Figure 4. Surface B; (a) Combo 1RC and (b) a 2D collage of the RL-RTI models, made by photomerging the greyscale Normals Visualizations exports from RTIViewer in Photoshop The RL-RTI models are the most detailed, while the Combo 1 model is the most detailed of the 3D models. The scale shown is $25 \mathrm{~cm}$. For practical purposes, only a selection of the results is shown here. All result images, including of the remaining methods, are available in full resolution online. 


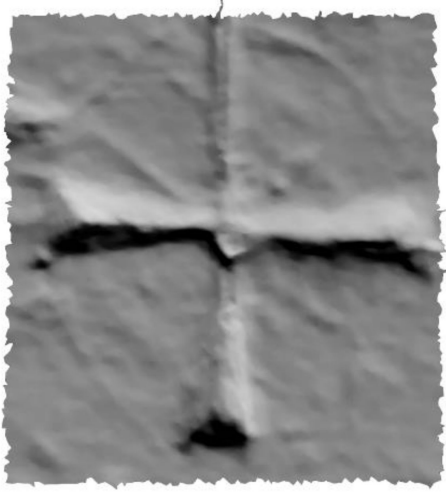

(a)
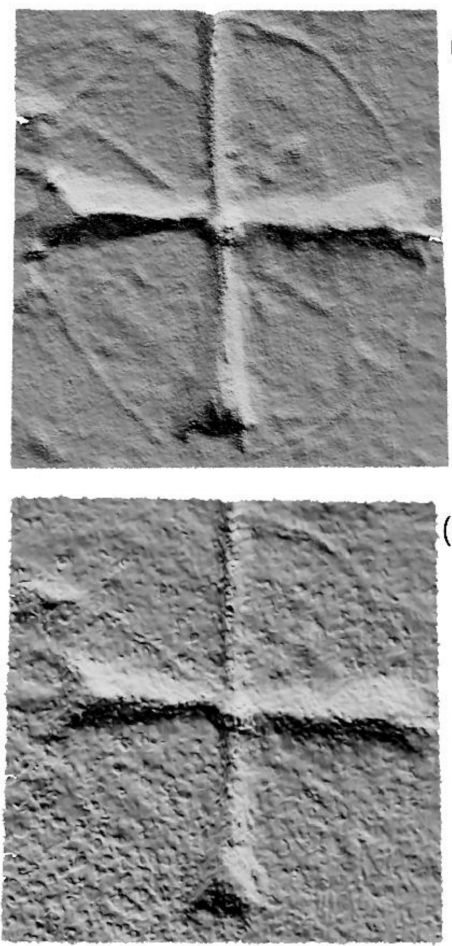

(d)
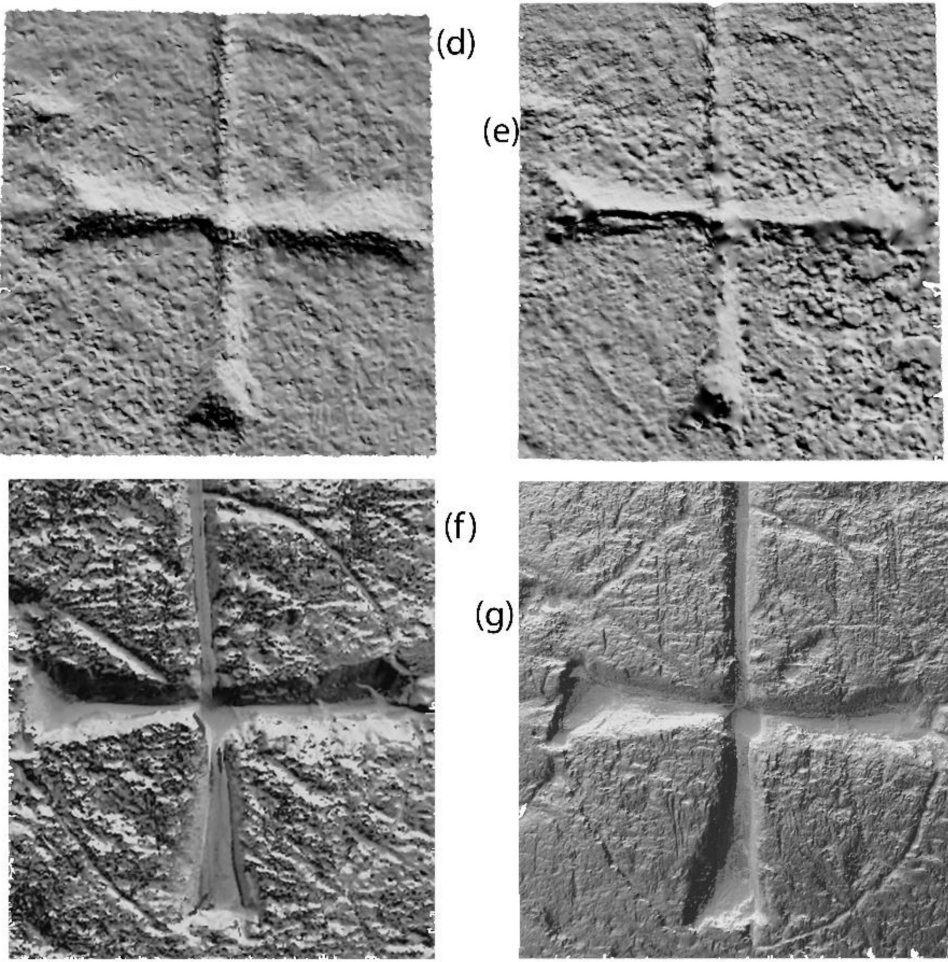

(f)

(g)
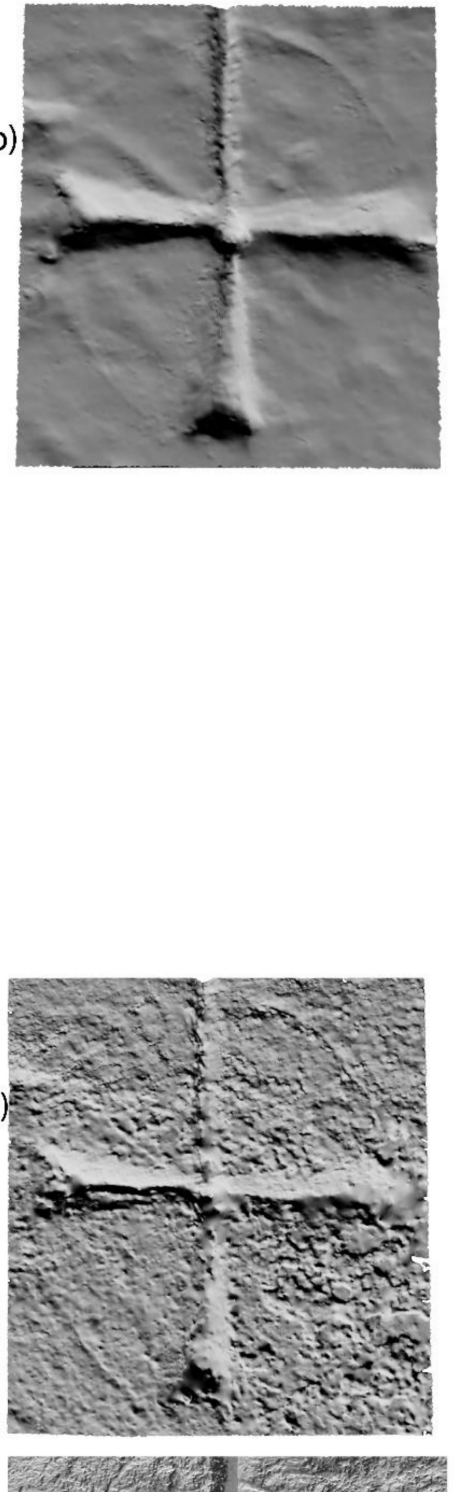

(c)
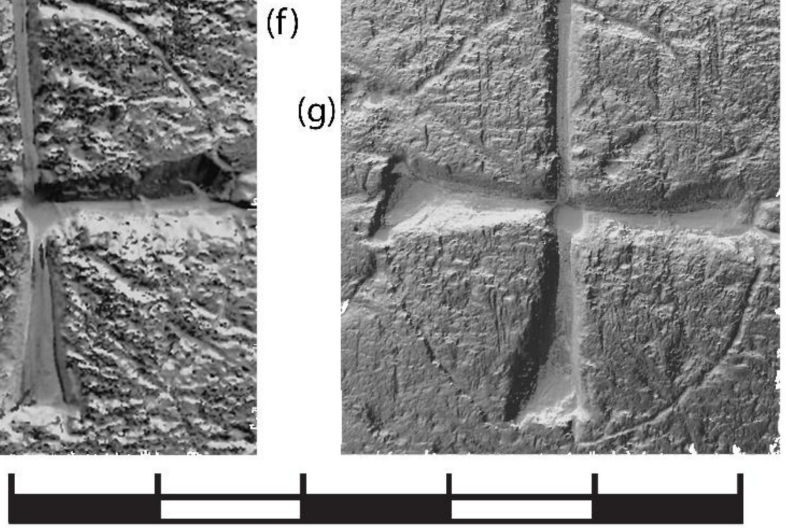

Figure 5. Detail from Surface A. (a) IBM-MetaShape (MS); (b) IBM-RC; (c) Combo 1-RC; (d) Combo 2-MS; (e) Combo 2-RC; (f) H-RTI; and (g) RL-RTI. The RTI models are the most detailed, while the Combo 1 model is the most detailed of the 3D models. The Combo 2 models are the least detailed and have more noise than the other 3D models. The scale shown is $5 \mathrm{~cm}$. All images are available in full resolution online. 


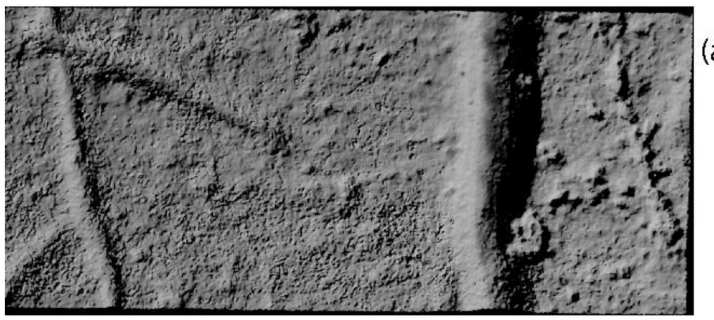

(a)

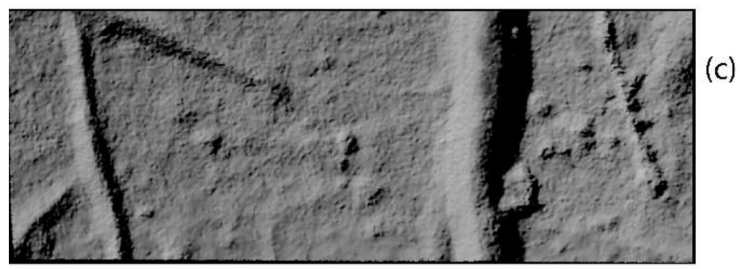

(b)
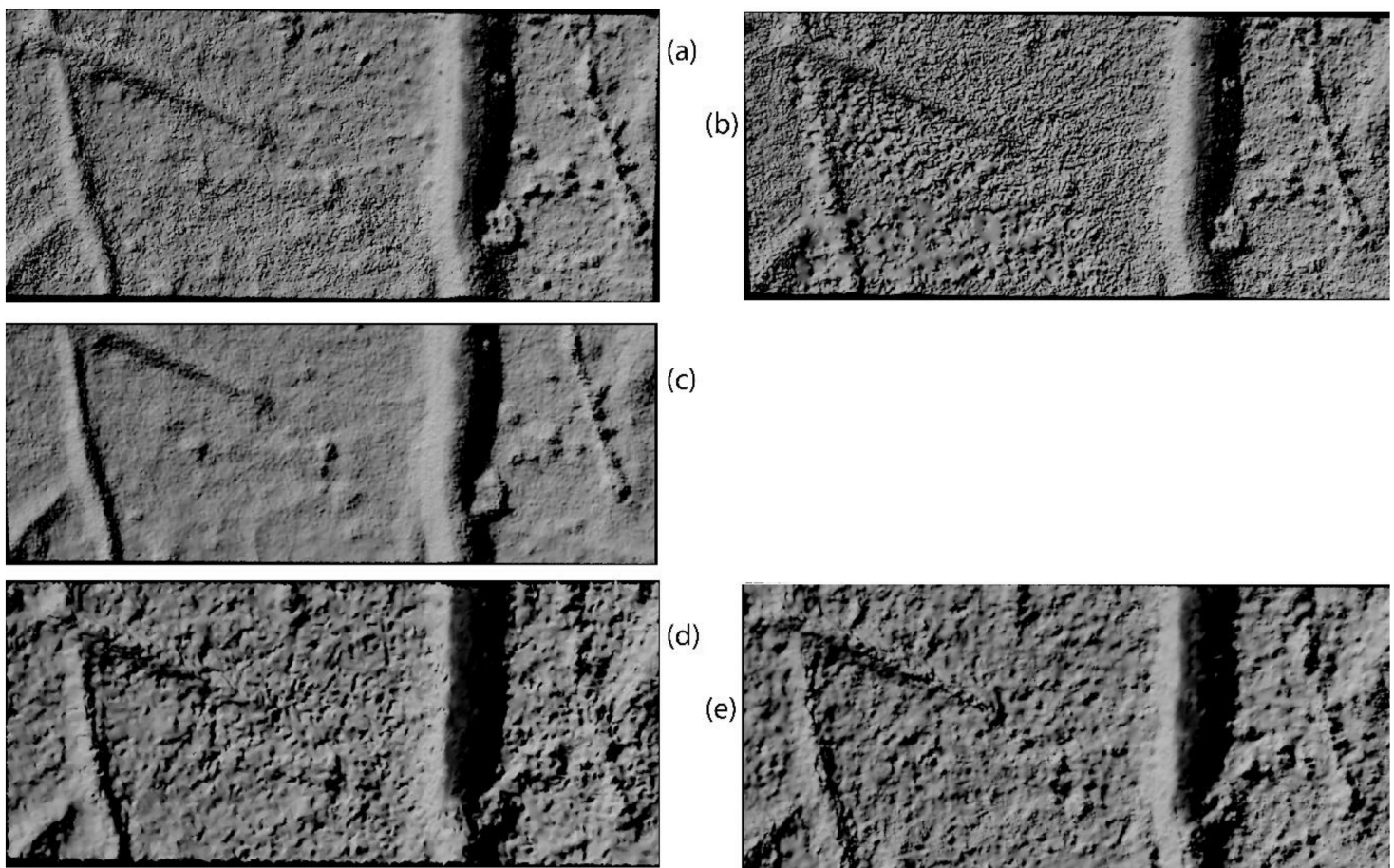

(d)
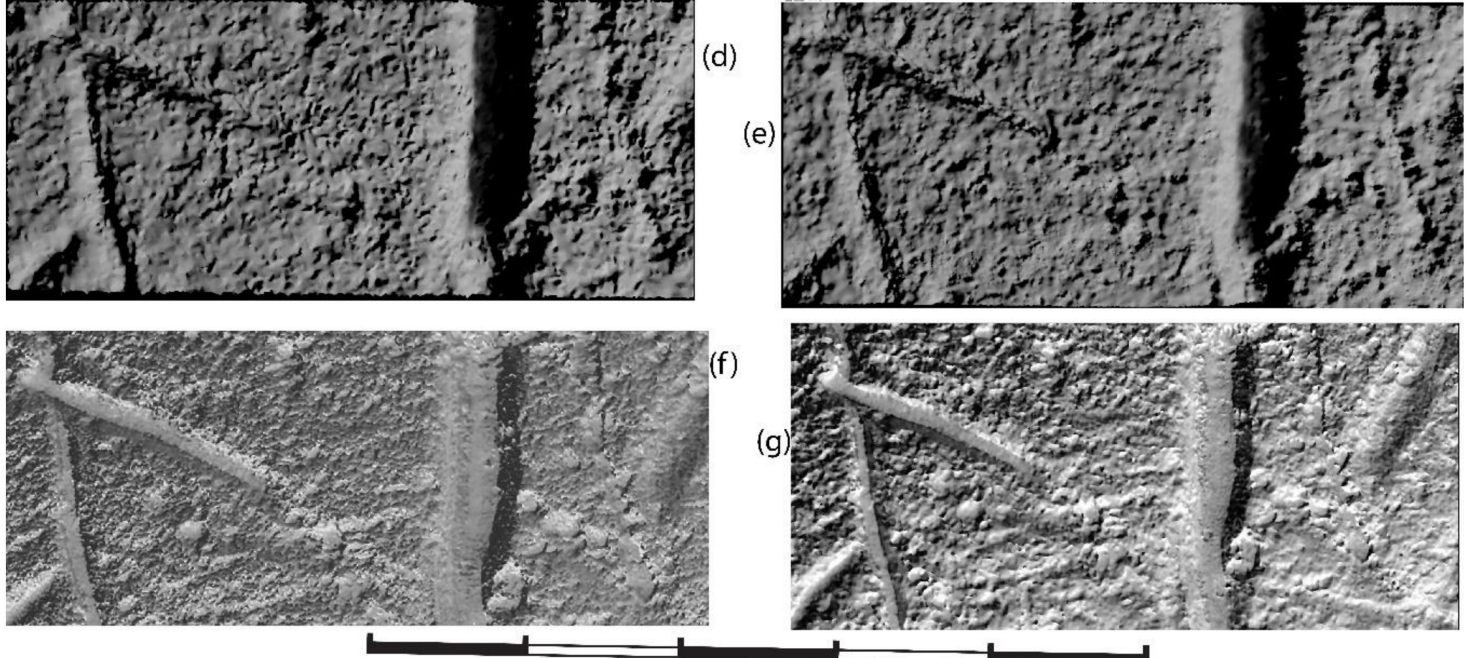

Figure 6. Detail from Surface B. (a) IBM-MS; (b) IBM-RC; (c) Combo 1-RC; (d) Combo 2-MS; (e) Combo 2-RC; (f) H-RTI; and (g) RL-RTI. The RTI models are the most detailed, while the Combo 1 model is the most detailed and has the least amount of noise of the 3D models. The Combo 2 models are the least detailed and have more noise than the other 3D models. The scale shown is $5 \mathrm{~cm}$. All images are available in full resolution online.

All the 3D models made with RealityCapture were slightly more detailed and less pixelated than those made by MetaShape. On the other hand, all the models made with RealityCapture had some areas that were less detailed or more noisy than in the corresponding areas of the models made by MetaShape (see for instance the IBM-RC model in Figure 6b versus the IBM-MS model in Figure 6a). Another interesting result was that MetaShape was able to align an area of Surface A which was photographed with little overlap for Combo 2, while RealityCapture could not.

\section{Discussion}

IBM and RTI are handy tools for recording and analyzing surfaces with miniature elevation differences; for example, recording incised surfaces, monitoring the deterioration old buildings over time, and examining different layers of paint on a painting. However, their potential is restricted as the methods are mostly used separately [10]. This study has highlighted different approaches to using IBM and/or RTI. Although the study tested a limited amount of equipment and software on only two surfaces, the results indicate that no single method is perfect for all purposes (Table 5). 
Table 5. The methods compared. For further elaborations of the evaluations, see the corresponding sections in the Results chapter.

\begin{tabular}{|c|c|c|c|c|}
\hline Method & Usability & Time-efficiency & Cost-efficiency & Accuracy \\
\hline $\begin{array}{c}\text { IBM-MS } \\
\text { IBM image acquisition and IBM } \\
\text { post-processing (MetaShape) }\end{array}$ & \multirow{2}{*}{$\begin{array}{c}\text { Good } \\
\text { + Can record large and uneven surfaces } \\
+ \text { Results in 3D models, high usability } \\
\div \text { Well- and even-lit surfaces needed } \\
\div \text { Ample workspace needed for uneven surfaces } \\
\quad \div \text { Photographic texture maps only }\end{array}$} & $\begin{array}{c}\text { Poor } \\
\div \text { Low time-efficiency off-site }\end{array}$ & Good & Good \\
\hline $\begin{array}{c}\text { IBM-RC } \\
\text { IBM image acquisition and IBM } \\
\text { post-processing } \\
\text { (RealityCapture) }\end{array}$ & & $\begin{array}{c}\text { Excellent } \\
+ \text { Higher time-efficiency off-site }\end{array}$ & Poor & \\
\hline $\begin{array}{l}\text { H-RTI } \\
\text { Highlight RTI image acquisition } \\
\text { and RTI post-processing }\end{array}$ & $\begin{array}{c}\text { Fair } \\
+ \text { Can record larger and more uneven surfaces than RL-RTI } \\
\div \text { Best suited for flat and small to medium surfaces } \\
\quad \text { Dark surroundings required } \\
\div \text { Ample workspace required for larger surfaces } \\
\quad \div \text { Results in RTI models, low usability }\end{array}$ & Fair & Excellent & $\begin{array}{c}\text { Excellent } \\
+ \text { Highly detailed RTI models }\end{array}$ \\
\hline $\begin{array}{l}\text { RL-RTI } \\
\text { RTI dome image acquisition and } \\
\text { RTI post-processing }\end{array}$ & $\begin{array}{c}\quad+\text { Provides its own illumination } \\
\quad+\text { Not much workspace needed } \\
\div \text { Best suited for flat and small surfaces } \\
\div \text { Results in RTI models, low usability }\end{array}$ & Excellent & Good & $\begin{array}{c}\text { Excellent } \\
+ \text { Highly detailed RTI models }\end{array}$ \\
\hline $\begin{array}{c}\text { Combo } 1 \\
\text { RTI dome image acquisition and } \\
\text { IBM post-processing }\end{array}$ & $\begin{array}{c}\text { Good } \\
\text { + Provides its own illumination } \\
\text { + Not much workspace needed } \\
+ \text { Results in both 3D and RTI models } \\
\div \text { Best suited for flat and small to medium surfaces } \\
\quad \div \text { Photographic texture maps only }\end{array}$ & $\begin{array}{l}\text { Fair } \\
\div \text { Large number of pictures } \\
\text { results in low time-efficiency } \\
\text { off-site }\end{array}$ & $\begin{array}{l}\text { Poor } \\
\div \text { Large number of pictures } \\
\text { requires more expensive IBM } \\
\text { software }\end{array}$ & $\begin{array}{c}\text { Excellent } \\
+ \text { The most detailed 3D models } \\
\text { of the techniques tested }\end{array}$ \\
\hline $\begin{array}{l}\text { Combo } 2 \\
\text { RTI dome image acquisition and } \\
\text { both RTI and IBM } \\
\text { post-processing }\end{array}$ & $\begin{array}{c}\text { Excellent } \\
\text { + Provides its own illumination } \\
\text { + Not much workspace needed } \\
\text { + Results in both 3D and RTI models } \\
+ \text { Both photographic and surface texture maps available } \\
\quad \text { - Best suited for flat and small to medium surfaces }\end{array}$ & $\begin{array}{l}\text { Good } \\
+ \text { Low number of pictures } \\
\text { results in higher time-efficiency } \\
\text { off-site }\end{array}$ & $\begin{array}{l}\text { Good } \\
+ \text { Low number of pictures } \\
\text { allows use of low-cost software }\end{array}$ & $\begin{array}{c}\text { Fair } \\
+ \text { Highly detailed RTI models } \\
\div \text { The least detailed 3D models } \\
\text { of the techniques tested }\end{array}$ \\
\hline
\end{tabular}


If usability is the most important factor, IBM has an advantage as it is the only one able to record surfaces of most shapes and sizes. For example, if one wanted to record incisions on a very curved sculpture, methods utilizing RTI image acquisition and/or RTI post-processing would not work; the curvatures would obstruct the lights and shadows too much for either proper recording or model generation. On the other hand, the sculpture could easily be recorded by using IBM, provided adequate illumination and image acquisition workspace were available. Furthermore, the methods generating 3D models (IBM, Combo 1 and Combo 2) have high result usability as 3D models can be used for many different purposes. However, methods using only 3D software for post-processing (IBM and Combo 1) have low time-efficiency, especially when using MetaShape. Using RealityCapture will speed up the post-processing substantially, even more so when processing many pictures. MetaShape is the least expensive option, but if time-efficiency is more important than cost-efficiency, RealityCapture is recommended. The differences regarding the accuracy of the 3D models made by the two software packages are minor. While the level of detail is generally higher in the RealityCapture models, some examples have less detailed and more noisy parts than the corresponding parts of the MetaShape models.

If time-efficiency, cost-efficiency and accuracy are the most important factors, the pure RTI methods are better options. The software is free, and the RTI post-processing results in very accurate RTI models which may be manipulated in various ways to enhance the details even further. Both image acquisition and post-processing are highly time-efficient, especially when using a less cost-efficient RTI dome (RL-RTI).

There is a strong case for combining IBM and RTI, however. While not time-efficient or cost-efficient, combining RL-RTI image acquisition with IBM post-processing (Combo 1) generates the most accurate 3D models of the techniques tested here. Why is this? Could the reason be just that the pictures taken for Combo 1 was taken closer and with a better lens? For instance, as seen in Table 4, the GSD value of the IBM model of Surface A is $0.1 \mathrm{~mm}$, while the Combo 2 model has a GSD value of $0.07 \mathrm{~mm}$. To examine this, a well-lit picture from each of the 28 camera positions taken of Surface A for Combo 1 was post-processed as IBM-RC; if the changing illumination provided by the RL-RTI setup did not contribute to the added detail quality, this test model should be just as detailed as the Combo 1 model. As seen in Figure 5, the test model (Figure 7b) is clearly less accurate than the Combo 1 model (Figure 7a), even though the pictures they are based on have the same GSD values.

Another suggestion to explain the added accuracy of the Combo 1 technique was that the camera might have moved slightly when taking the images and that this movement in effect added up to a lot more than 28 camera positions. This explanation was also dismissed, as close inspection revealed that there had been virtually no camera movement. To conclude, the added accuracy of the Combo 1 models must be attributed to the IBM software being able to detect more details and avoid data acquisition error because of the RL-RTI setup.

RL-RTI image acquisition with RTI post-processing before IBM post-processing (Combo 2) also has some merits. Firstly, the process efficiently generates both RTI and 3D models, allowing high result usability. Secondly, the low number of pictures after the original pictures are "distilled" by the RTI software can easily be processed by cheaper software packages such as MetaShape. Thirdly, by using Combo 2, surface texture maps may be generated instead of photographic texture maps; i.e., texture maps based on the Normals Visualization exports from the RTI models instead of the original photographic color maps (Figure 8). Neither the photographic texture maps (Figure 8a,c), nor the 3D models themselves (Figures 3-6) exhibit the level of details shown by the surface textures (Figure $8 \mathrm{~b}, \mathrm{~d}$ ). All surfaces recorded by both IBM and RTI may have the RTI result projected onto the 3D models afterwards, but only Combo 2 has the option of producing surface texture during the 3D model generation. The surface texture could be said to be misleading since the Combo $23 \mathrm{D}$ models are less accurate than the other IBM models. So, the question to be asked is, which type of accuracy matters most: The 3D model accuracy or the texture accuracy? If the top priority is for the 3D models to be analyzed as $3 \mathrm{D}$ surfaces, then $3 \mathrm{D}$ model quality is clearly important. If the main goal 
of the documentation is to analyze or disseminate the incisions as cultural heritage, the amount of details one can see might be the most important. A bonus is that the original pictures post-processed using Combo 2 may also be post-processed using Combo 1 in cases where the added quality of the 3D models matters.

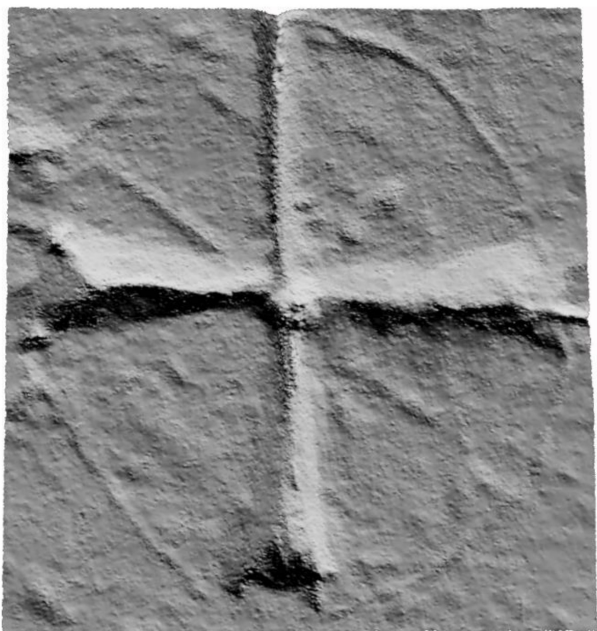

(a)

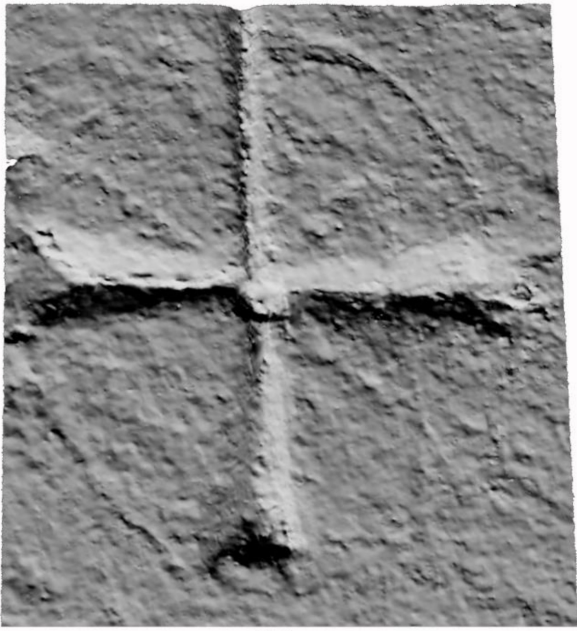

(b)

Figure 7. Detail from Surface A: (a) Combo 1; (b) a test model where only one image per camera position were included. The comparison shows that the variation in illumination in the images used for generating the Combo 2 model have made it more detailed than the test model. The scale shown is $2 \mathrm{~cm}$. Both images are available in full resolution online.
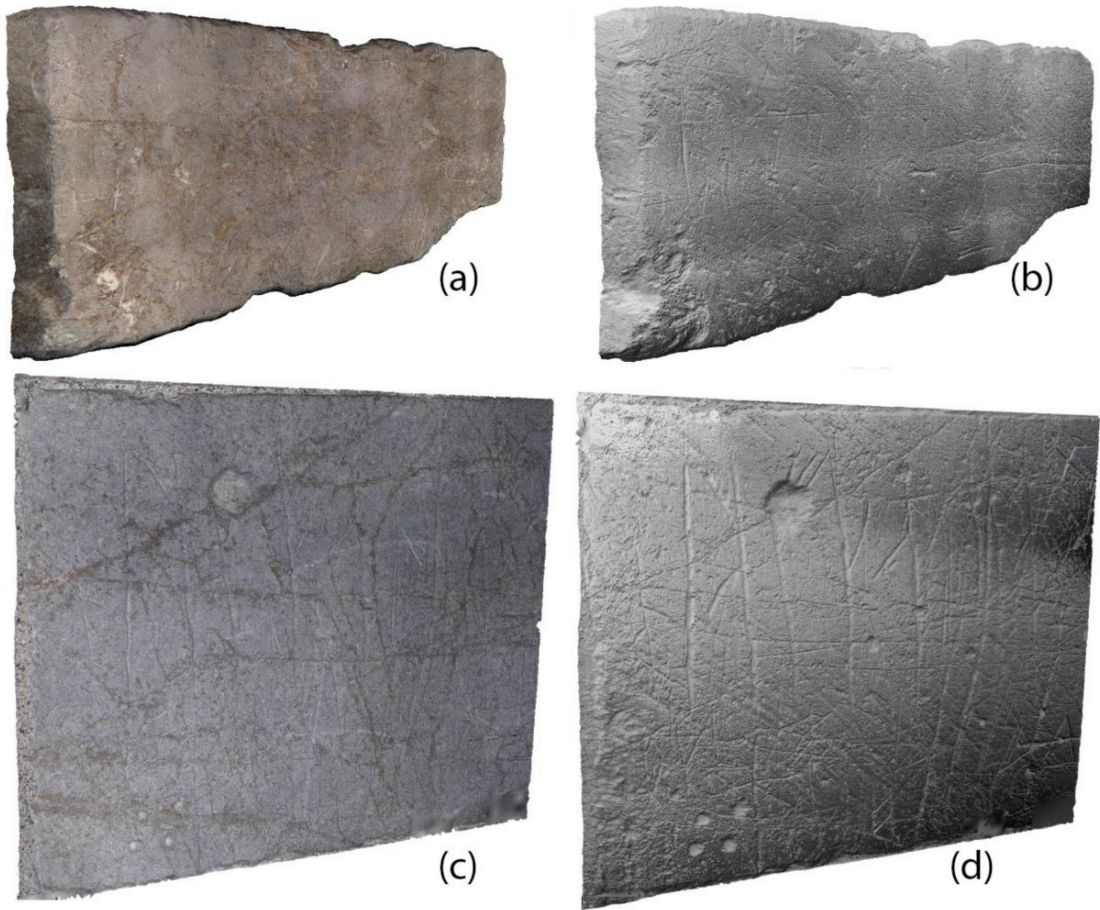

Figure 8. The recorded surfaces with IBM generated photographic texture maps (left) and RTI generated surface texture maps (right); (a) Surface A, Combo 2MS; (b) Surface A, Combo 2MS; (c) Surface B, Combo 2RC; and (d) Surface B, Combo 2RC. The surface texture maps in images b) and d) are based only on lights and shadows from the RTI processing and show great levels of details obscured in the photographic texture maps in images (a) and (c). All images are available in full resolution online. 


\section{Conclusions}

Two surfaces bearing miniature incisions were recorded by IBM and RTI, as well as two novel ways of combining these methods. The aim of this article was to assess these methods in terms of their usability, time-efficiency, cost-efficiency and accuracy. Furthermore, all 3D models were generated by using two 3D processing software packages, MetaShape and RealityCapture, to examine their influence on the reviewed factors. The following conclusions can be drawn from this study:

1. None of the methods tested were optimal in all regards. Consequently, the choice of method must be based upon a prioritization of the reviewed factors.

2. The two techniques that combine IBM and RTI gave positive results. Combo 2 (RTI image acquisition by an RTI dome, combined with post-processing using RTI software first and IBM software subsequently) appears to be the overall best method based on the reviewed factors. The process generates both RTI and 3D models and does this efficiently in terms of both time and cost. Although the resulting 3D models are less accurate than those produced by the other methods, the models may be fitted with highly detailed surface texture maps derived from the RTI processing. The numerous original pictures may also be post-processed directly by using more expensive IBM software (Combo 1). Although this method is not cost- or time-efficient, it generates the most accurate 3D models of the methods tested.

3. The more expensive, RealityCapture, was a lot more time-efficient than MetaShape. However, in cases where the same pictures could be processed by both software packages, the accuracy of the 3D models generated showed minor differences. The evaluation of the IBM software packages ability to generate high detail quality remains inconclusive.

Some shortcomings in our research should be pointed out. Because of time and availability constraints, not all methods were tested on all surfaces. In addition, the MetaShape models were not attempted made with Custom Face Count settings, which presumably would have added more details but possibly also more noise. In general, more variations of on-site and off-site setup should be tested on more surfaces to examine how this will affect the reviewed factors.

Supplementary Materials: All figures and source images are available online at: https://doi.org/10.6084/m9. figshare.c.4948227.v2.

Author Contributions: Conceptualization, methodology, software, formal analysis, investigation, resources, data curation, writing - original draft preparation, visualization, supervision, project administration, funding acquisition D.-Ø.E.S.; Writing-review and editing, validation; E.N. All authors have read and agreed to the published version of the manuscript.

Funding: This research was funded by the Norwegian Research Council, via The Norwegian Institute of Cultural Heritage Research's Institutional Strategic Focus on Buildings, module 2: "Knowledge, surveillance and communications. Technology and Methods." The goal of this project is to contribute knowledge in a way that buildings and interior may be managed so that today's users get good experiences and connection to the heritage. The focus of module 2 is documentation of archaeological remains of buildings, and documentation of surfaces of standing buildings.

Acknowledgments: The authors wish to thank the Norwegian Research Council for funding, and the leader of the Institutional Strategic Focus on Buildings at the Norwegian Institute of Cultural Heritage Research, Tone Olstad, for allowing this project to be a part of that program. And thanks to Øystein Digre and Ronald Hübner at the Nidaros Cathedral's Workshop, who facilitated the documentation of the building stone Surface A. Thanks to all colleagues who read and commented the draft: Chris McLees, Fredrik Berg, Therese Edman, Kristoffer Brink, Tone Olstad, Julian Patrick Cadamarteri, Magnar Mojaren Gran, and Marte Iversen Rønning.

Conflicts of Interest: The authors are employed by The Norwegian Institute of Cultural Heritage Research (NIKU), which among other services offers digital documentation as a commercial service.

\section{Appendix A-Specification and Settings of Hardware Used}

IBM, Surface A: Canon EOS 6D camera, Canon EF $50 \mathrm{~mm}$ lens. F-stop: f/22. Exposure time: 1/8-1/20 sec. ISO speed: 200-500. Exposure bias +0,7 step. Metering mode: partial. Dimensions: $5472 \times$ 3648 pixels. GSD: $0,1 \mathrm{~mm}$. 
IBM, Surface B: Nikon D90 camera, Nikon AF-S Micro-Nikkor $60 \mathrm{~mm}$ lens. F-stop: f/4-f/.5. Exposure time: $1 / 250-1 / 400 \mathrm{sec}$. ISO speed: 400 . Metering mode: pattern. Dimensions: $4288 \times 2848$ pixels. GSD: 0.

RL-RTI, Combo 1 and 2, Surface B: Canon EOS 6D camera, Zeiss Distagon 28 mm lens. F-stop: f/2.8. Exposure time: 1/30 sec. ISO speed: 1000. Metering mode: pattern. Dimensions: $5472 \times 3648$ pixels.

RL-RTI, Combo 1 and 2, Surface A: Canon EOS 6D camera, Zeiss Distagon $28 \mathrm{~mm}$ lens. F-stop: f/2.8. Exposure time: $1 / 30 \mathrm{sec}$. ISO speed: 1250. Metering mode: pattern. Dimensions: $5472 \times 3648$ pixels.

H-RTI, Surface A: Canon EOS 6 D camera, Canon EF 50 mm lens. F-stop: f/2.2. Exposure time: 1/60 sec. ISO speed:500. Exposure bias: +0.7 step. Metering mode: partial. Dimensions: $5472 \times 3648$ pixels.

\section{Appendix B - Specification and Settings of Software Used}

Blender, version 2.8a: Free software by the Blender Foundation. Downloaded from www.blender.org. CloudCompare, version 2.10.2: Free software by EDF's R\& D. Downloaded from www.cloudcompare.org. MeshLab, version 2016.12: Free software by the ISTI-CNR research center. Downloaded from www.meshlab.net. Settings: Radiance Scaling shader. Grey Descriptor, enhancement: 1.0.

MetaShape Professional, version 1.6.1.10009 (IBM-MS, Combo 1, Combo 2): Commercial software by Agisoft LCC. Alignment parameters: accuracy: highest, generic preselection: no, reference preselection: no, key point limit: 40 000, tie point limit: 4000 (Exception, Combo 2; key point limit: 400 000, tie point limit: 40 000). Depth maps generation parameters: quality: ultra high, depth filtering: moderate (Surface A), aggressive (Surface B, IBM), reuse depth maps: Yes. Reconstruction parameters: surface type: arbitrary, interpolation: enabled, depth maps quality: ultra high, face count: high, interpolation: enabled, reuse depth maps: yes. Texturing parameters: mapping mode: orthophoto, blending mode: mosaic, texture size: 4096, enable hole filling: no.

RealityCapture, version 1.0.3.10393 (IBM-RC, Combo 1, Combo 2): Commercial Software by CapturingReality. Alignment settings: max features per mpx: 10 000, max features per image: 40 000, image overlap: low, image downscale factor: 1 , max feature reproduction error: 2.0, force component rematch: no, background feature detection: no, background thread priority: low, preselector features: 10 000, detector sensitivity: medium, distortion model: brown3. Reconstruction settings: quality level: high, maximal vertex count per part: 5000 000, detail decimation factor: 1, adaptive blending start: 0.45 , smoothing 1.5 , visibility filtering region: 2 , default grouping factor: 1 , low-texture grouping factor: 0,25 , default noise factor: 1 , low-texture noise factor: 2 , mesh filtration filter radius: 3 , filter strength: 2 . Texturing: texturing style: visibility-based, coloring style: texturing-based, unwrapping style: adaptive texel size.

RTIBuilder, version 2.02 (H-RTI): Format: LRGB Polynomial Texture Maps (PTM). Free software downloaded from www.culturalheritageimaging.org.

RTI Processor, version 0.3 (RL-RTI, Combo 1, Combo 2): Free software by Professor Kirk Martinez at university of Southampton. Downloaded from https://github.com/kmartinez/rti.

RTIViewer, version 1.1. Free software downloaded from www.culturalheritageimaging.org.

\section{Appendix C - Specifications and Cost of Equipment Used}

Cameras:

Canon EOS 6D: \$2000

Nikon D90: \$1462

Lenses:

Canon EF 24 mm f/1.8: $\$ 2000$

Canon EF $50 \mathrm{~mm}$ f/1.4: $\$ 415$

Nikon AF-S Micro-Nikkor 60 mm f/1.4: \$1189

Zeiss Distagon $\mathrm{T}^{*} 28 \mathrm{~mm} \mathrm{f} / 2$ : $\$ 1233$ 
Mount:

Leofoto LT mount: \$300

Shutter remote:

\section{Canon RS-80N3: \$100}

Flash:

Phottis Mitros Remote Flash: \$500

Other:

\section{RTI Starter Kit: $\$ 650$}

\section{References}

1. Demesticha, S. KARAVOI: A Programme for the Documentation of Ship Graffiti on Medieval and post-Medieval Monuments of Cyprus. In ISBSA 14: Baltic and Beyond. Change and Continuity in Shipbuilding. Proceedings of the Fourteenth International Symposium on Boat and Ship Archaeology; Litwin, J., Ed.; Gdansk National Maritime Museum: Gdansk, Poland, 2017; pp. 135-141.

2. Champion, M. Medieval Graffiti: The Lost Voices of England's Churches, 1st ed.; Crown Publishing Group: New York, NY, USA, 2015.

3. Demesticha, S.; Delouca, K.; Trentin, M.G.; Bakirtzis, N.; Neophytou, A. Seamen on Land? A Preliminary Analysis of Medieval Ship Graffiti on Cyprus. Int. J. Naut. Archaeol. 2017, 46, 346-381. [CrossRef]

4. Samaan, M.; Deseilligny, M.P.; Heno, R.; De la Vaissière, E.; Roger, J. Close-range photogrammetric tools for epigraphic surveys. J. Comput. Cult. Herit. 2016, 9, 1-18. [CrossRef]

5. Caine, M.; Maggen, M.; Altaratz, D. Combining RTI \& SFM. A Multi-Faceted approach to Inscription Analysis; Electronic Imaging \& the Visual Arts: Florence, Italy, 2019; pp. 97-104.

6. Sammons, J.F.D. Application of Reflectance Transformation Imaging (RTI) to the study of ancient graffiti from Herculaneum, Italy. J. Archaeol. Sci. Rep. 2018, 17, 184-194. [CrossRef]

7. Frood, K. Elisabeth \& Howley, Applications of Reflectance Transformation Imaging (RTI) in the Study of Temple Graffiti. In Thebes in the First Millenium BC; Pischikova, K., Budka, E., Griffin, J., Eds.; Cambridge Scholars Publishing: Newcastle upon Tyne, UK, 2014; pp. 625-639.

8. Cosentino, A.; Stout, S.; Scandurra, C. Innovative Imaging Techniques for Examination and Documentation of mural paintings and historical graffiti in the catacombs of San Giovanni. Int. J. Conserv. Sci. 2015, 6, 23-34.

9. Kjellman, E. From 2D to 3D: A Photogrammetric Revolution in Archaeology? University of Tromsø: Tromsø, Norway, 2012; p. 102.

10. Pamart, A.; Ponchio, F.; Abergel, V.; Alaoui M'darhri, A.; Corsini, M.; Dellepiane, M.; Morlet, F.; Scopigno, R.; De Luca, L. A COMPLETE FRAMEWORK OPERATING SPATIALLY-ORIENTED RTI in A 3D/2D CULTURAL HERITAGE DOCUMENTATION and ANALYSIS TOOL. ISPRS Ann. Photogramm. Remote Sens. Spat. Inf. Sci. 2019, 573-580. [CrossRef]

11. Porter, S.T.; Huber, N.; Hoyer, C.; Floss, H. Portable and low-cost solutions to the imaging of Paleolithic art objects: A comparison of photogrammetry and reflectance transformation imaging. J. Archaeol. Sci. Rep. 2016, 10, 859-863. [CrossRef]

12. Miles, J.; Pitts, M.; Pagi, H.; Earl, G. New applications of photogrammetry and reflectance transformation imaging to an Easter Island statue. Antiquity 2014, 88, 596-605. [CrossRef]

13. Shi, W.; Kotoula, E.; Akoglu, K.; Yang, Y.; Rushmeier, H. CHER-Ob: A Tool for Shared Analysis in Cultural Heritage. EUROGRAPHICS Work. Graph. Cult. Herit. 2016. [CrossRef]

14. Giachetti, A.; Ciortan, I.M.; Daffara, C.; Marchioro, G.; Pintus, R.; Gobbetti, E. A novel framework for highlight reflectance transformation imaging. Comput. Vis. Image Underst. 2018, 168, 118-131. [CrossRef]

15. Graichen, T. Photogrammetry and RTI—Combination Tests. 2020. Available online: http://www.tgraichen. de/?page_id=561 (accessed on 22 April 2020).

16. Frank, E.B. Integrating Multispectral Imaging, Reflectance Transformation Imaging (RTI) and Photogrammetry for Archaeological Objects. 2017. Available online: http://www.emilybeatricefrank. com/combining-computational-imaging-techniques (accessed on 22 April 2020). 
17. Mathys, A.; Brecko, J.; Semal, P. Comparing 3D digitizing technologies: What are the differences? In Proceedings of the 2013 Digital Heritage International Congress (DigitalHeritage), Marseille, France, 28 October-1 November 2013; Volume 1, pp. 201-204. [CrossRef]

18. Boehler, W.; Marbs, A. 3D Scanning and Photogrammetry for Heritage Recording: A Comparison. In Proceedings of the 12th International Conference Geoinformatics, Gävle, Sweden, 7-9 June 2004.

19. Hess, M.; Macdonald, L.W.; Valach, J. Application of multi - modal 2D and 3D imaging and analytical techniques to document and examine coins on the example of two Roman silver denarii. Herit. Sci. 2018, 1-22. [CrossRef]

20. Iglhaut, J.; Cabo, C.; Puliti, S.; Piermattei, L.; O'Connor, J.; Rosette, J. Structure from Motion Photogrammetry in Forestry: A Review. Curr. For. Rep. 2019, 5, 155-168. [CrossRef]

21. Palomar-Vazquez, J.; Baselga, S.; Viñals-Blasco, M.-J.; García-Sales, C.; Sancho-Espinós, I. Application of a combination of digital image processing and 3D visualization of graffiti in heritage conservation. J. Archaeol. Sci. Rep. 2017, 12, 32-42. [CrossRef]

22. Mudge, M.; Malzbender, T.; Schroer, C.; Lum, M. New Reflection Transformation Imaging Methods for Rock Art and Multiple-Viewpoint Display. In Proceedings of the 7th International Symposium on Virtual Reality, Archaeology and Intelligent Cultural Heritage VAST2006, Nicosia, Cyprus, 30 October-4 November 2006; pp. 195-202. [CrossRef]

23. Reflectance Transformation Imaging-Guide to Highlight Image Capture v. 2.0. 2013. Available online: http://culturalheritageimaging.org/What_We_Offer/Downloads/RTI_Hlt_Capture.Guide_v2_0.pdf (accessed on 18 May 2020).

24. Berrier, S.; Tetzlaff, M.; Ludwig, M.; Meyer, G. Improved appearance rendering for photogrammetrically acquired 3D models. Digit. Herit. 2015, 1, 255-262. [CrossRef]

25. Agisoft MetaShape User Manual-Professional Edition, version 1.5; Agisoft LLC, St. Petersburg, Russia. 2019. Available online: https://www.agisoft.com/pdf/metashape-pro_1_5_en.pdf (accessed on 14 May 2020).

26. Lojewski, T. Document analysis at AGH University of Science and Technology. In Proceedings of the 2018 IEEE International Conference on Metrology for Archaeology and Cultural Heritage, Cassino, Italy, 22-24 October 2018.

(C) 2020 by the authors. Licensee MDPI, Basel, Switzerland. This article is an open access article distributed under the terms and conditions of the Creative Commons Attribution (CC BY) license (http://creativecommons.org/licenses/by/4.0/). 